ness and wretchedness in the world of to-day. And although we know that there is nothing final in that world State, although we see it only as something to be reached and passed, although we are sure there will be no such sitting down to restore and perfect a culture as the positivists foretell, yet few people can persuade themselves to see anything beyond that except in the vaguest and more general terms. That world State of more efficient, more vivid, beautiful and eventful people is, so to speak, on the brow of the hill, and we cannot see over-though some of us can imagine great uplands beyond and something, something that glitters elusively, taking first one form and then another, through the haze. We can see no detail, we can see nothing definable, and it is simply, I know, the sanguine, necessity of our minds that makes us believe those uplands of the future are still more gracious and splendid than we can either hope or imagine. But of things that can be demonstrated we have none.

Yet I suppose most of us entertain certain necessary persuasions, without which a moral life in this world is neither a reasonable nor a possible thing. All this paper is built finally upon certain negative beliefs that are incapable of scientific establishment. Our lives and powers are limited, our scope in space and time is limited, and it is not unreasonable that for fundamental beliefs we must go outside the sphere of reason and set our feet upon Faith. Implicit in all such speculations as this, is a very definite and quite arbitrary belief, and that belief is that neither humanity nor in truth any individual human being is living its life in vain. And it is entirely by an act of faith that we must rule out of our forecasts certain possibilities, certain things that one may consider improbable and against the chances, but that no one upon scientific grounds can call impossible. One must admit that it is impossible to show why certain things should not utterly destroy and end the entire human race and story, why night should not presently come down and make all our dreams and efforts vain. It is conceivable, for example, that some great unexpected mass of matter should presently rush upon us out of space, whirl sun and planets aside like dead leaves before the breeze, and collide with and utterly destroy every spark of life upon this earth. So far as positive human knowledge goes, this is a conceivably possible thing. There is nothing in science to show why such a thing should not be. It is conceivable, too, that some pestilence may presently appear, some new disease, that will destroy, not IO or 15 or 20 per cent. of the earth's inhabitants as pestilences have done in the past, but 100 per cent., and so end our race. No one, speaking from scientific grounds alone, can say - that cannot be. And no one can dispute that some great disease of the atmosphere, some trailing cometary poison, some great emanation of vapour from the interior of the earth, such as Mr. Shiel has made a brilliant use of in his "Purple Cloud," is consistent with every demonstrated fact in the world. There may arise new animals to prey upon us by land and sea, and there may come some drug or a wrecking madness into the minds of men. And finally there is the reasonable certainty that this sun of ours must some day radiate itself towards extinction; that at least must happen, it will grow cooler and cooler, and its planets will rotate ever more sluggishly until some day this earth of ours, tideless and slow moving, will be dead and frozen, and all that has lived upon it will be frozen out and done with. There surely man must end. That of all such nightmares is the most insistently convincing.

And yet one doesn't believe it

At least I do not. And I do not believe in these things because I have come to believe in certain other things, - in the coherency and purpose in the world and in the greatness of human destiny. Worlds may freeze and suns may perish, but there stirs something within us now that can never die again.

Do not misunderstand me when I speak of the greatness of human destiny.

If I may speak quite openly to you, I will confess that, considered as a final product, I do not think very much of myself or (saving your presence) my fellow creatures. I do not think I could possibly join in the worship of humanity with any gravity or sincerity. Think of it. Think of the positive facts. There are surely moods for all of us when one can feel Swift's amazement that such a being should deal in pride. There are moods when one can join in the laughter of Democritus; and they would come oftener were not the spectacle of human littleness so abundantly shot with pain. But it is not only with pain that the world is shot-it is shot with promise. Small as our vanity and carnality makes us, there has been a day of still smaller things. It is the long ascent of the past that gives the lie to our despair. We know now that all the blood and passion of our life was represented in the Carboniferous time by somethingsomething, perhaps, cold-blooded and with a clammy skin, that lurked between air and water, and fled before the giant amphibia of those days.

For all the folly, blindness and pain of our lives, we have come some way from that. And the distance we have travelled gives us some earnest of the way we have yet to go.

Why should things cease at man? Why should not this rising curve rise yet more steeply and swiftly? There are many things to suggest that we are now in a phase of rapid and unprecedented development. The conditions under which men live are changing with an ever-increasing rapidity, and, so far as our knowledge goes, no sort of creatures have ever lived under changing conditions without undergoing the profoundest changes themselves. In the past century there was more change in the conditions of human life than there had been in the previous thousand years. A hundred years ago inventors and investigators were rare scattered men, and now invention and inquiry is the work of an organised army. This century will see changes that will dwarf those of the nineteenth century as those of the nineteenth dwarf those of the eighteenth. One can see no sign anywhere that this rush of change will be over presently, that the positivist dream of a social reconstruction and of a new static culture phase will ever be realised. Human society never has been quite static, and it will presently cease to attempt to be static. Everything seems pointing to the belief that we are entering upon a progress that will go on, with an ever-widening and ever more confident stride, for ever. The reorganisation of society that is going on now beneath the traditional appearance of things is a kinetic reorganisation. We are getting into marching order. We have struck our camp for ever and we are out upon the roads.

We are in the beginning of the greatest change that humanity has ever undergone. There is no shock, no epoch-making incident-but then there is no shock at a cloudy daybreak. At no point can we say, here it commences, now, last minute was night and this is morning. But insensibly we are in the day. If we care to look we can foresee growing knowledge, growing order, and presently a deliberate improvement of the blood and character of the race. And what we can see and imagine gives us a measure and gives us faith for what surpasses the imagination.

It is possible to believe that all the past is but the beginning of a beginning, and that all that is and has been is but the twilight of the dawn. It is possible to believe that all that the human mind has ever accomplished is but the dream before the awakening. We cannot see, there is no need for us to see, what this world will be like when the day has fully come. We are creatures of the twilight. But it is out of our race and lineage that minds will spring, that will reach back to us in our littleness to know us better than we know ourselves, and that will reach forward fearlessly to comprehend this future that defeats our eyes. All this world is heavy with the promise of greater things, and a day will come, one day in the unending succession of days, when beings, beings who are now latent in our thoughts and hidden in our loins, shall stand upon this earth as one stands upon a footstool, and shail laugh and reach out their hands amidst the stars.

\section{THE WEST INDIAN AGRICULTURAL}

\section{CONFERENCE, 1902}

THE fourth Agricultural Conference under the presidency of Dr. D. Morris, Imperial Commissioner of Agriculture for the West Indies, was held on January 4 to 6 . The opening ceremony was attended by the Governor and the chief members of the military and civil services of the Colony. The delegates, some sixty in number, included representatives of the scientific and educational staffs of all the West Indian colonies.

The president delivered an address reviewing the work of the Department of Agriculture during its three years of existence. Under the head of sugar industry, experimental stations were at work at British Guiana, Barbados, Antigua and St. Kitts raising and testing large numbers of seedling canes, and extensive series of experiments were being carried out with manures. The insect and fungoid diseases of the sugarcane were being carefully worked out, and schemes for central

No. I 684, VOL. 65] 
factories at Barbados and Antigua were gradually taking shape. The diseases of cacao were !receiving careful attention, and amongst subsidiary industries the best method of converting lime juice into citrate of lime was being investigated; attempts were being made to establish a trade in sweet potatoes between Barbados and London, to grow Irish potatoes for the London market, and to develop the onion industry in Antigua, Montserrat and Dominica ; and plantations of the Central American rubber (Castilloa elastica) had been started at Trinidad and Tobago. A bee expert had been employed for several months to visit and advise bee-keepers, and lately an illustrated pamphlet containing information respecting bee-keeping in the West Indies had been published. Very favourable conditions existed in many of the West Indian colonies for raising horses, cattle and small stock, and efforts were being made to improve native breeds by the importation of stallion ponies, Maltese jacks and iennies, pedigree bulls, pigs, sheep, goats and poultry. The direct fruit trade recently established between Jamaica and the United Kingdom by means of a subsidised steamship service had proved entirely successful, and it was difficult to over-estimate the possibilities in this direction, in which many of the smaller West Indian islands might participate.

Agricultural education had formed an important part of the work done; courses of lectures in agriculture were being delivered in all parts of the West Indies to school teachers, and by this means the subject was being introduced into the primary schools. In the higher grade schools and colleges it was sough to establish lectureships in agricultural science; a lecturer had been provided by the Department at Barbados and Jamaica, and favourable reports had been received upon the results of their work. Seven agricultural scholarships had been founded, and it was hoped soon to be able to increase the number in order to afford opportunity to the most promising boys in the smaller islands to obtain sound agricultural teaching. Agricultural schools at St. Vincent, Dominica and St. Lucia had been established, at which seventy boys were being maintained for three or four years free of cost to their parents and carefully trained in the science and practice of agriculture. Attached to the schools were experiment stations, where the boys carry on all light operations and raise a portion of their own food. A series of lectures to planters had been given in Barbados the full text of which would shortly be published. Agricultural shows under the auspices of the Imperial Department of Agriculture were now regularly held at seven of the islands, and these shows were gradually drawing attention to the better cultivation and preparation of produce and bringing prominently into notice the varied resources of the islands.

Besides the journal of the Imperial Department of Agriculture (West Indian Bulletin), of which the last number of the second volume was in the press, twelve pamphlets, containing in the aggregate $417 \mathrm{pp}$, had been published since the last conference. These pamphlets contain information specially applicable to tropical conditions, and 30,000 copies are in course of being distributed. The principal subjects dealt with are :"The General Treatment of Insect Pests" (first and second editions), "Scale Insects of the Lesser Antilles" (part i.), "Cultivation of Vegetables," "Hints for cooking Sweet Potatoes," "Bee-keeping in the West Indies," "Manures and Leguminous Plants at Barbados, I 898-1901," "Hints for School Gardens," "Seedling and other Canes in the Leeward Islands, I900-I90I," "Seedling and other Canes at Barbados, I9or." Of "Nature Teaching " (pp. I 2 and 199) 2000 copies have been published and nearly all distributed. The Department contemplates the publication of a fortnightly paper, to be called the Agricultural Neres, containing hints and advice on all points of interest to the West Indies.

The sugar industry was the first subject taken up for discussion by the Conference; short papers were read by those engaged in sugar-cane experiments in the various colonies, summarising the progress made during the past year; a discussion ensued in which the agricultural representatives took an important part. While no seedling could be put forward at present to displace the old and weil-tried varieties, it was felt that the progress made encouraged the view that the production of seedlings was destined to play an important part in the future existence of the sugar-cane industry in the West Indies. The accounts given of recent manurial experiments confirmed the importance of active nitrogenous manures but tended to show that in many soils phosphatic manures did not increase the yield. The general consensus of opinion was in favour of supplementing the experimental station plots by trials upon a large scale on the estates, and this method has been already adopted in several colonies.

The proceedings included important papers by Mr. H. H. Cousins (Government chemist, Jamaica) and Mr. Joseph Shore (Jamaica), on "The Sugar Industry of Jamaica," and accounts of the life-history of the lady bird borer (Sphenophorus sacchari), by Mr. Maxwell Lefroy, and of "The Field Treatment of Cane Tops in reference to Fungoid Disease," by Mr. A. Howard.

On the second day, papers on agricultural education were read by Mr. A. B. McFarlane (principal of the Teachers' Training College, Jamaica), Mr. W. R. Buttenshaw (lecturer in agricultural science, Jamaica) and Messrs. J. E. Reece, J. A. Harbin and C. M. Martin, inspectors of schools at Barbados, Grenada and the Leeward Islands. An educational section, with the Bishop of Barbados as chairman and Mr. C. M. Martin as secretary, reported upon questions connected with agricultural teaching at primary schools. A chemical section, with Prof. J. B. Harrison (British Guiana) as chairman and Prof. J. P. d'Albuquerque (Barbados) secretary, reported upon chemical methods in sugar-cane work.

Papers were also read on "Suggestions for Regulating the Quality of Exported Fruit," by Mr. Sydney Olivier (Colonial Secretary, Jamaica), "The Preparation of Citrate of Lime," by Mr. Francis Watts (Government chemist, Leeward Islands), "Scale Diseases," by Mr. H. Maxwell Lefroy (entomologist to the Department), "Agricultural Boards," by Mr. Sydney Olivier, "The Preparation of Essential Oils," by Mr. Hart (Superintendent of the Botanic Gardens, Trinidad), "The Removal of Epiphytic Vegetation on the Stems of Cacao and Lime Trees," by Mr. A. Howard (mycologist to the Department), and "The Aloe Industry of Barbados," by Mr. W. G. Freeman (technical assistant to the Department).

\section{J. P. D'Albuquerque.}

\section{THE LEONID SHOWER OF I9OI.}

I $\mathrm{T}$ now seems possible to give a brief review of the character of the Leonid shower which occurred last November, a considerable number of reports being available for the purpose. Certain other results obtained in various quarters of the globe doubtless still remain unpublished, but it is not likely that they will materially differ from those already before us.

In England the display of Leonids cannot be said to have been a conspicuous or a plentiful one, though it was decidedly stronger than in either of the years 1899 or I900. Fortunately, the sky was clear on the nights following November I4 and I5, and a large number of observations were secured in different parts of the country. On the morning of November $15, \mathrm{Mr}$. $\mathrm{H}$. Corder at Bridgwater watched the firmament for an hour and a half and saw 50 meteors, three-quarters of the number being Leonids, so that the horary rate of their apparition was about 25. Mr. E. C. Willis, of Norwich, found the hourly number 22 on the same morning, while on the following morning it was I8. Mr. J. R. Henry, of Dublin, observing from $\mathrm{Ih}$. to 3.30 , saw Leonids as bright as the first and second magnitude falling at the rate of 12 per hour. The maximum was apparently attained just before the morning twilight began to overpower the fainter stars. The horary numbers quoted above may be fairly con sidered to approximate the truth. It is true that some other observers saw fewer meteors, but as they were engaged in recording the individual paths, a considerable number must have altogether escaped their notice.

But the real maximum of the shower certainly occurred after sunrise in England; this is proved by observations from America, where the meteors were far more numerous, though the display was only of secondary importance. Mr. E. L. Larkin, at the observatory on Echo Mountain, S. California, counted 297 meteors on November I $5,4 \mathrm{~h}$. to $5 \mathrm{~h}$. a.m. (local time), so they were falling at the rate of 5 per minute. The maximum was at about 4h. $20 \mathrm{~m} .-25 \mathrm{~m}$. a.m. One fireball left a streak for 14 minutes, and the meteors generally were very brilliant, two being estimated twenty times as bright as Venus, three ten times as bright, twelve five times as bright, and twenty-five equal to Venus. Forty were equal to Jupiter. At Ladd Observatory, Providence, the number seen was 2 per minute on the morning of November I 5 , while at several other places in the States the rate was 3 or 4 per minute between about $3 \mathrm{~h}$. $30 \mathrm{~m}$. and $5 \mathrm{~h}$. $30 \mathrm{~m}$. a.m.

NO. I 684, VOL. 65] 